\title{
X-ray pelvimetry: prognosis of delivery by cephalous-pelvic confrontation in Cotonou
}

\author{
S. Adisso ${ }^{1 *}$, N. Atrevy ${ }^{2}$, E. L. Adisso ${ }^{3}$, Mukanire ${ }^{4}$, R. X. Perrin ${ }^{5}$, E. Alihonou ${ }^{1}$ \\ ${ }^{1}$ University Clinic of Gynecology-Obstetrics (CUGO), CNHU, Cotonou \\ ${ }^{2}$ Abomey-Calavi Polytechnic college (EPAC), UAC, Benin \\ ${ }^{3}$ Department of Radiology, CNHU, Cotonou \\ ${ }^{4}$ Lagune Mother and Child Hospital, Cotonou \\ ${ }^{5}$ Panzi General Hospital, Bukavu, DRC
}

Received: 22 June 2017

Accepted: 19 July 2017

*Correspondence:

Dr. S. Adisso,

E-mail: noudeli2014@gmail.com

Copyright: (C) the author(s), publisher and licensee Medip Academy. This is an open-access article distributed under the terms of the Creative Commons Attribution Non-Commercial License, which permits unrestricted non-commercial use, distribution, and reproduction in any medium, provided the original work is properly cited.

\begin{abstract}
Background: The mechanical dystocia constitutes one of the causes of maternal death during labour. Reducing the incidence of complications of dystocia means recognize the factors induce dystocia. That justifies X-ray pelvimetry and cephalic fetal ultrasonography to predict the outcome of labour. This survey aims at establishing the prognosis of labour by a cephalous-pelvic confrontation.

Methods: This study was realised at CUGO and HOMEL, reference maternity hospitals in Cotonou from $28^{\text {th }}$ March to $4^{\text {th }}$ August 2006. That was a prospective study. During prenatal visit, pregnant women who had pelvis abnormality were recruited after their consent after counselling about exploration of their pelvis and fetal cephalic diameters. Pregnant women in their ninth month underwent to X-ray pelvimetry and fetal biometric ultrasonography.

Results: During that study, 122 pregnant women in their ninth month were recruited. Favourable prognosis $(36.89 \%)$ : natural delivery $31.15 \%$; (concordance rate is $84.44 \%$ ). Uncertain prognosis $(18.85 \%)$ : caesarean section $(10.66 \%)$, natural delivery $(7.37 \%)$. Unfavourable prognosis $(44.26 \%): 40.16 \%$ deliveries by caesarean section. Concordance rate is $90.74 \%$.

Conclusions: The cephalous-pelvic confrontation is a reliable prognosis method. It is recommendable in our maternity hospitals to prevent complications of dystocia, a cause of maternal death.
\end{abstract}

Keywords: Cephalous-pelvic confrontation, Dystocia, X-ray pelvimetry

\section{INTRODUCTION}

No more dying during labour is a legitimate goal that the obstetricians aim at and tackle every day to make it happen. Among the causes of maternal death include dystocia, one of the involved factors in their occurrence being the pelvis. ${ }^{1}$

During the labour, the fetus, to cross the mother's pelvis, confronts the diameters of its presentation with the diameters of the mother. ${ }^{2,3}$ The outcome of this confrontation may be unfavorable, thus making it impossible to deliver by a low tract. The delay or absence of a relevant intervention to alleviate this situation may lead to uterine rupture. This fearful complication of mechanical dystocia often occurs, either in conditions of ignorance of the actual dimensions of the pelvis or is due to poor obstetrical practices.

Nowadays, X-ray pelvimetry and ultrasound exam have been made available in national reference hospitals. These explorations consider the diameter of the pelvis 
and the fetal head; they contribute to the prognosis and the choice of the delivery tract. ${ }^{4-6}$ This study aims at setting up the profile, the different types of pelvis of the pregnant women and the prognosis of the delivery by the cephalous-pelvic confrontation.

\section{METHODS}

The present study was conducted at the Medical Imaging Department of the National University Hospital Center "Hubert Koutoukou Maga" (NUHC-HKM) with collaboration of the University Clinic of Gynecology and Obstetrics (UCGO) of NUHC-HKM and Prenatal service of Lagune Maternity Hospital for the Mother and Child (HOMEL) in Cotonou.

To perform the X-ray pelvimetry, we used an X-ray machine equipped with a powerful generator in good condition allowing the use of high voltage; Two cassettes of $36 \mathrm{~cm} \mathrm{x} 43 \mathrm{~cm}$ equipped with fast screens; X-ray films of $36 \mathrm{~cm} \times 43 \mathrm{~cm}$ dimension with a high sensitivity; An automatic X-ray film processor; THOMS material (a Bakelite plate adjustable in height leaded centimeter and comprising a frame, a sliding pointer provided with a graduated vertical ruler in centimeter for the height measurement of table top-edge of the pubis, Bakelite Vertical ruler leaded mounted on a bracket graduated in centimeters). The photographs were made by medical imaging engineers trained in that technique. Our sample consists of 122 pregnant women in their ninth month, with an X-ray pelvimetry indication.

The present study was a prospective cross-sectional study of women in their ninth month of pregnancy. It took place from March $28^{\text {th }}$ to August $4^{\text {th }}, 2006$. It focused on women attending one of the last prenatal consultations either at the CUGO of CNHU-HKM, or at prenatal service of HOMEL and having an X-ray pelvimetry indication after clinical examination by a GynecologistObstetrician doctor. The inclusion criteria selected for our sample were: pregnant women at their ninth month, with an X-ray pelvimetry indication and addressed to the CNHU radiology department. Excluded were pregnant women that were not in their ninth month, who did not have a fetal ultrasound exam at their ninth month, the twin pregnancy and breech presentation cases.

Each pregnant woman benefited from a profile and face picture of the pelvis according to Thoms's technique. ${ }^{7}$ Following the performance of these pictures, we measured the diameters of the main brim: the median transverse (Tmed), the promonto-retropubic (PRP), the maximum transverse (Tmax).

The performed measurements made it possible to classify the pelvis into morphological types according to Thoms's criteria and anatomical types according to Magnin's criteria. $^{7,8}$ In the morphological classification according to Thoms, there are: the Dolichopellic pelvis with a GWP $>$ T max, the Mesatipellic pelvis with a GWP $=\mathrm{T}$
Max or $<\mathrm{T} \max$ of $1 \mathrm{~cm}$, the Brachypellic pelvis with a GWP $<\mathrm{T} \max$ of 1 to $3 \mathrm{~cm}$, the Platypellic pelvis with a PRP < T max of more than $3 \mathrm{~cm}$. In the anatomical classification, according to Magnin, the pelvis is pure flattened $(\mathrm{BAP})$ when the PRP $<10.5 \mathrm{~cm}$ and the $\mathrm{T}$ med $=$ $12.5 \mathrm{~cm}$; It is transversally narrow (BTR) if the PRP = $10.5 \mathrm{~cm}$ and the $\mathrm{T}$ med $<12.5 \mathrm{~cm}$; Flattened and Generally narrow (BAGR) in case of a predominant decrease in PRP; Transversally and generally constricted (BTGR) in case of a predominant decrease in Tmed; Generally narrow (BGR) if decrease of two diameters.

The Magnin index is the sum of the median transverse (Tmed) and the promonto-retropubian (PRP). ${ }^{8}$ The prognosis of the labour is said to be very favorable when the Magnin index is equal to or greater than 23; Favorable when it is between 22 and 23; Reserved between 21 and 22; uncertain between 20 and 21 and poor for a value less than 20. In practice Magnin index confronts the fetal biparietal diameter allows the use of Magnin's diagram (Figure 1), to determine the delivery tract. $^{3,8}$

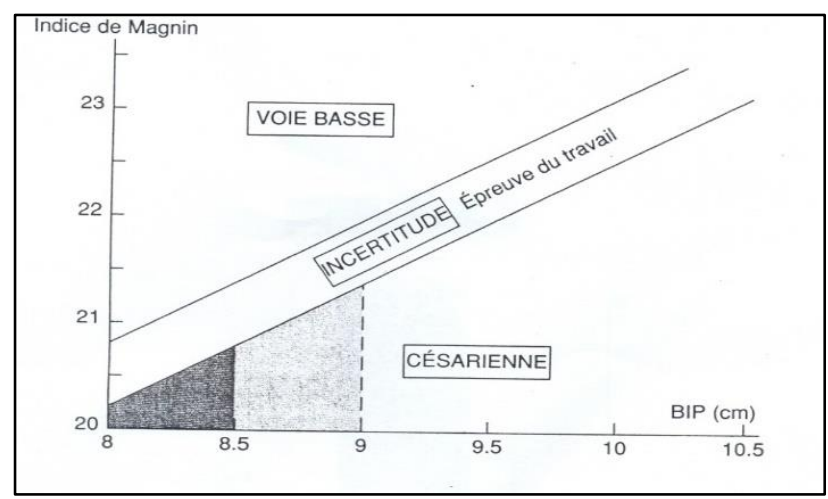

Figure 1: Magnin's cephalous-pelvic confrontation diagram.

After taking the pictures and the measurement of pelvic diameters, the confrontation with the data of fetal ultrasound exam at the ninth month, based on Magnin's diagram was used to study the prognosis of the labour. The results were recorded on the data collection form and on the examination slip. These slips were returned to the services where the pregnant women were being followed.

The variables studied were: age, height, and pregnant women gender, morphological and anatomical type of the pelvis, the prognosis of the labour and the delivery mode performed.

The data collection technique was based on an interview with the pregnant woman for filling in the predetermined survey form. For ethical reasons, we explained to pregnant women to have their consent, the interests of $\mathrm{X}$ ray pelvimetry for the foresight of the delivery mode and the effects of X-rays on the fetus during the ninth month of pregnancy. Data processing was done with the software Epi Info 6.04, French version. 


\section{RESULTS}

The present results focused on the socio-anthropometric characteristics of pregnant women, the distribution of pelvis according to anatomical and morphological classifications, ultrasound measurements of biparietal diameter of the fetal head, cephalous-pelvic confrontation, prognosis of delivery, prognosis rate of concordance with the delivery mode finally realized.

\section{Socio-anthropometric characteristics of pregnant women}

The average age of pregnant women was 25 years (range 16-39 years). The majority were between 20 and 29 years old, either $69.67 \mathrm{pc}$. The average size of pregnant women was $156 \mathrm{~cm}$ (range 134-174 cm). The majority were between $1.50 \mathrm{~m}$ and $1.69 \mathrm{~m}$, either 102/122 (83.61 pc).

The majority of the pregnant women were nulliparous and primiparous, either $106 / 122 \quad(86.88 \mathrm{pc})$. The multiparous were only 3 ( $2.46 \mathrm{pc})$ Classification of pelvis (Table 1).

Table 1: Distribution of pelvis according to Magnin's anatomical classification.

\begin{tabular}{|llll|}
\hline $\begin{array}{l}\text { Type of } \\
\text { pelvis }\end{array}$ & No. & Frequency & $\begin{array}{l}\text { Cumulative } \\
\text { frequency }\end{array}$ \\
\hline BTR & 59 & 48.36 & 48.36 \\
\hline BGR & 26 & 21.31 & 69.67 \\
\hline BAGR & 32 & 26.32 & 95.90 \\
\hline BTGR & 01 & 0.82 & 96.72 \\
\hline Normal & 04 & 03.28 & 100.00 \\
\hline Total & 122 & 100 & \\
\hline
\end{tabular}

\section{Distribution morphological classification according to} Thoms's pelvis

The pelvis of the brachypellic type was the most frequent with 56 pregnant women out of $122(45,90 \mathrm{pc})$. The platypellic type was the least common with $2 / 122$ (1.64 pc) (Table 2).

Table 2: Distribution of pregnant women according to size and Magnin Index. Distribution of fetal biparietal diameters.

\begin{tabular}{|lllllll|}
\hline $130-139 \mathrm{~cm}$ & 02 & 00 & 00 & 00 & 00 \\
\hline $140-149 \mathrm{~cm}$ & 05 & 06 & 05 & 00 & 00 \\
\hline $150-159 \mathrm{~cm}$ & 05 & 19 & 17 & 14 & 05 \\
\hline $160-169 \mathrm{~cm}$ & 02 & 02 & 14 & 15 & 09 \\
\hline $170-179 \mathrm{~cm}$ & 00 & 00 & 00 & 00 & 02 \\
\hline Total & 14 & 27 & 36 & 29 & 16 \\
\hline
\end{tabular}

The mean value for biparietal diameter studied was 88.39 $\mathrm{mm}$. The smallest value for BIP was $80 \mathrm{~mm}$ and the largest value was $99.1 \mathrm{~mm}$. The majority 54/122 (44.26) were between 85 and $89 \mathrm{~mm}$ (Table 3).

Table 3: Frequency of prognosis according to cephalous-pelvic confrontation.

\begin{tabular}{|llll|}
\hline Prognosis & Number & $\begin{array}{l}\text { Frequency } \\
(\text { pc) }\end{array}$ & $\begin{array}{l}\text { Cumulative } \\
\text { Frequency } \\
\text { (pc) }\end{array}$ \\
\hline Favorable & 45 & 36.89 & 36.89 \\
\hline Uncertain & 23 & 18.85 & 55.74 \\
\hline Reserved & 54 & 44.26 & 100.00 \\
\hline Total & 122 & 100.00 & - \\
\hline
\end{tabular}

Out of 23 pregnant women with uncertain prognosis, 5 had a normal delivery and 13 went for a caesarean section for dynamic and mechanical dystocia indications.

Calculation of labour prognosis test characteristics.

- $\quad$ Mobilized $(\mathrm{Mo})=\mathrm{A} /(\mathrm{A}+\mathrm{C})=49 / 56=0.8750=$ $87.50 \%$

- $\quad$ Specificity $(\mathrm{Sp})=\mathrm{D} /(\mathrm{D}+\mathrm{B})=38 / 43=0.8837=$ $88.37 \%$

- Positive predictive value $(\mathrm{VPP})=\mathrm{A} /(\mathrm{A}+\mathrm{B})=$ $49 / 54=0.9074=90.74 \%$

- $\quad$ Negative predictive value $(\mathrm{VPN})=\mathrm{D} /(\mathrm{D}+\mathrm{C})=$ $38 / 45=0.8444=84.44 \%$ (Table 4$)$.

Table 4: Concordance rate between prognosis and delivery mode finally realized.

\begin{tabular}{|llll|}
\hline & $\begin{array}{l}\text { Caesarean } \\
\text { section }\end{array}$ & $\begin{array}{l}\text { Normal } \\
\text { delivery }\end{array}$ & Total \\
\hline $\begin{array}{l}\text { Reserved } \\
\text { prognosis }\end{array}$ & $\begin{array}{l}49(40.16 \%) \\
05(B)\end{array}$ & $54(\mathrm{~A}+\mathrm{B})$ \\
$\begin{array}{l}\text { Favorable } \\
\text { prognosis }\end{array}$ & $07(\mathrm{C})$ & $\begin{array}{l}38(31.15 \%) \\
(\mathrm{D})\end{array}$ & $45(\mathrm{C}+\mathrm{D})$ \\
\hline Total & $56(\mathrm{~A}+\mathrm{C})$ & $43(\mathrm{~B}+\mathrm{D})$ & $\begin{array}{l}99 \\
(\mathrm{~A}+\mathrm{B}+\mathrm{C}+\mathrm{D})\end{array}$ \\
\hline
\end{tabular}

\section{DISCUSSION}

\section{Socio-anthropometric characteristics of pregnant women}

Our sample consisted of 122 Black pregnant women. The average age of pregnant women was 25 years. The youngest was 16 years old and the oldest was 39 years old. The majority were between 20 and 29 years, either 69.67 per cent.

Sample of present study was relatively young as the one worked on by Cissé and collaborators. ${ }^{9}$ The majority of them had a size between $1.50 \mathrm{~m}$ and $1.69 \mathrm{~m}$, either 83.61per cent.

The majority of our pregnant women were nulliparous and primiparous, either 86.88 per cent. 


\section{Anatomical types of pelvis}

The present series consists of 96.72 per cent of shrunken pelvis with 48.36 per cent of transversely narrowed pelvis (Table 1). This high percentage of BTR is characteristic of African women pelvis as shown by Matulewicz and also reported by Merger and Collaborators but remains much higher than that of the French women. ${ }^{5,10}$

\section{Morphological distribution of pregnant women according to Thoms's classification}

The morphological distribution of the different types of pelvis shows that the pelvis of brachypellic type is the most frequent in our sample either 45.90 per cent. This frequency of the brachypellic type is close to that of the French women which is 50 per cent, Bantu women from Congo which is 49.13 per cent; but largely deviates from those of the Democratic Republic of Congo (DRC) (ex Zaireans), which is 35 per cent, blacks and whites from the United States who are respectively 25 per cent and 32 per cent. $5,7,10,11$

\section{Distribution of pregnant women according to the size and Magnin index}

We noticed in this study that for pregnant women who have a size less than $1.50 \mathrm{~m}$, the Magnin index is less than 22 (Table 2); the prognosis of low delivery is uncertain. This observation was also made by Mahmood and Collaborators who also reported a significant increase of caesarean section rate in women of small size. ${ }^{12}$

\section{Frequency of prognosis according to cephalous-pelvic confrontation.}

The majority of the biparietal diameters studied (44.26 per cent) are between $85 \mathrm{~mm}$ and $89 \mathrm{~mm}$. The study of the prognosis of our delivery sample revealed 45 favorable prognosis (either 36.89 per cent), 23 uncertain prognosis (either 18.85 per cent) and 54 reserved prognosis (either 44.26 per cent) (Table 3 ). These rates are different from those reported by Schaal and collaborators which are 60 per cent in the favorable prognosis area, 24 per cent in the uncertain zone and 16 per cent in the reserved prognosis zone. ${ }^{13}$ This difference may be justified by the nature of our sample, which is composed only of women presenting a clinical indication for X-ray pelvimetry.

\section{Concordance between the prognosis and the realized delivery mode}

Out of the 45 favorable delivery prognosis (either 36.89 per cent), 38 pregnant women had a normal labour by low tract, a concordance rate of $84.44 \%$, linked here to the negative predictive value $(\mathrm{NPV}=0.84)$. For the uncertain prognosis, of the 23 uncertain prognosis (18.85 per cent), 5 pregnant women had a normal labour and 13 went for a caesarean section for dynamic and mechanical dystocia indications. The choice of delivery mode in these cases has been highly labour-oriented.

For the 54 (either 44.26 per cent) reserved prognosis, 49 (either 40.16 per cent) of pregnant women actually went for a caesarean section for reasons largely related either to the maternal pelvis (BGR and BTR) alone or to the maternal pelvis and to the fetal head (feto-pelvic disproportion), either a concordance rate of $90.74 \%$, linked here to the positive predictive value (PPV $=$ $0.9074 \approx 0.91$ ). The sensitivity of the prognosis test is about $87 \%$, and the specificity is $88 \%$.

The confidence level given to the diagram in this reserved prognosis area in our series is therefore 90.74 per cent. This close rate is that indicated by Magnin and Collaborators which is 9 out of $10 .{ }^{4}$ Note that there was a high rate of caesarean section in our series (69 cases out of 122 , either 56.55 per cent). This could be explained by the large number of shrunken pelvis in our sample $(96.72$ per cent) (Table 3 ). It is this high caesarean section rate that Langer and Schlaeder have tried to explain in these terms: The two main indications that may explain the rise in caesarean section are cicatricial uterus and dystocia. ${ }^{14}$

\section{CONCLUSION}

The fight against maternal morbidity and mortality associated with dystocia requires adequate material and human resources, such as x-ray pelvimetry, ultrasound machines and trained technicians in their use at affordable cost in reference hospitals. The use of Magnin's cephalous-pelvic confrontation diagram remains a benchmark in this fight, even though it does not address all the stages of the pelvis likely to be involved in dystocia. However, it proves to be a method of prognosis for reliable labour within limits, and recommended in our maternity wards, if necessary, to prevent complications related to dystocia, causes of maternal deaths.

\section{ACKNOWLEDGMENTS}

Authors would like to thank Mr. Philemon Mulongo for his availability in submitting this article.

Funding: No funding sources

Conflict of interest: None declared

Ethical approval: The study was approved by the Institutional Ethics Committee

\section{REFERENCES}

1. Thierry M. Obstetrical study of the pelvis: a historical overview. Verk K Acad Geneeskd Belg. 1955;57(3):199-228.

2. Anderson N. X-ray pelvimetric: helpful or harmful? J Fam Pract. 1983;17(3):405-12.

3. Lansac J, Berger C, Magnin G. Obstétrique pour le praticien. $2^{\text {nd }}$ édition Paris SIMEP;1990:59-192. 
4. Magnin P, Bremond A, Salomon B, Salussola JP, Felber M, Mamelle N. Diagram for the prognosis of cephalous-pelvic disproportions Application in 300 cases of pelvic contraction. J Gynecol Obstet Biol Reprod. 1975;4(7):975-87.

5. Merger R, Levy J, Melchior J. Précis d'obstétrique. $6^{\text {th }}$ éd. Paris Masson; 1995:14-367.

6. Dubois C, Duffour P, Quandalle F, Lanvin D, Levasseur M, Monnier JC. Breech presentation: management (304 cases). Contracept Fertil Sex. 1998;26(5):363-71.

7. Thoms H. Pelvimetry. Volume 1. New York Hoerper-harper; 1956.

8. Magnin P. Obstetrical Radiodiagnosis Scientific Expansion. 2nd Ed. Paris;1975:185-308.

9. Cisse CT, Kokaina C, Ndiaye O, Moreau JC. Trial of labour in moderate pelvic dystocia at Dakar University Teaching Hospital. J Gynecol Obstet Biol Reprod. 2004;33(4):312-8.

10. Matulewicz S, Accigliaro G. Radiopelvimetric study of the normal pelvis of Congolese women (Thoms classification). J Gynecol Obstet. 1967;66:167-174.
11. N'Doma H. Contribution to the radiological study of the Zairian woman's pelvis. Pub Med Afr. 1990;104:17-21.

12. Mahmood TA, Campbell DM, Wilson AW. Maternal height, shoe size and outcome of labour in white primigravidas: a prospective anthropométric study. BMJ. 1988;297(6647):515-7

13. Schaal JP, Riethmuller D, Martin A, Lemouel A, Quéreux C, Maillet R. Conduct during childbirth work Encycl Med Chir Obstetrics. (Elsevier, Paris); 5-049-D-27;1998:35.

14. Langer B, Schlaeder G. What does the caesarean rate mean in France. J Gynecol Obstet Biol Reprod. 1998;27(1):62-70.

Cite this article as: Adisso S, Atrevy N, Adisso EL, Mukanire, Perrin RX, Alihonou E. X-ray pelvimetry: prognosis of delivery by cephalous-pelvic confrontation in Cotonou. Int J Reprod Contracept Obstet Gynecol 2017;6:3737-41. 